\title{
Pancreatic Cancer Incidence, Mortality, and Survival in the SEER 17 Southern and Total United States (2000-2008)
}

\author{
Subi Gandhi
}

*Correspondence: gandhi@tarleton.edu

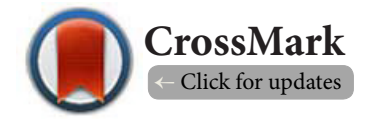

Department of Medical Laboratory Sciences and Public Health, Tarleton State University, 1333 West Washington Street, Stephenville, TX, USA.

\begin{abstract}
Background: There is a paucity of data comparing the rates and time trends of pancreatic cancer in the southern and the total United States (US), as the risk factors for this cancer are disproportionately distributed in these two regions. The aim of this study was to compare the burden of this fatal cancer in these large geographic regions.

Methods: Age-adjusted incidence and mortality rates for patients ( $\geq 40$ years) diagnosed with pancreatic cancer between 2000 and 2008 were calculated using the SEER 17 (southern and total US) data. Joinpoint regression was utilized to test the relationships between time and pancreatic cancer estimates. Relative, cause-specific, and conditional survival rates were also calculated for those diagnosed between 2000 and 2007.

Results: For both the study regions, an increase in incidence and mortality rates was observed in the older age groups ( $\geq 60$ years), males, and blacks. The overall mortality rate in the southern states was slightly higher $(26 \%)$ compared to the total US states (25\%), with similar incidence rates observed in the two regions (27\%). The annual percent increase (APC) in incidence rates was significant for all races and females in the southern states, but for all races and both the sexes in the total US. White females and black males in the southern states had higher three and five-year relative survival rates compared to their counterparts in the total US states.

Conclusion: Region-specific similarities and differences in incidence, mortality, and survival for pancreatic cancer were observed in the two regions. Particularly for the southern states, white females were at a significantly higher risk for developing this aggressive cancer compared to their male counterparts, and the incidence rate dramatically decreased for Asian/Pacific Islanders compared to other race/ethnic groups. These findings could have implications regarding preventive care services and treatment options for particular subgroups in the south.
\end{abstract}

Keywords: Pancreatic cancer, incidence, trends, mortality, relative survival, SEER Cancer Registries

\section{Introduction}

Pancreatic cancer is the fourth leading cause of cancer-related deaths among both males and females in the western world [1]. The international incidence rates of pancreatic cancer vary from five to ten cases per 100,000 a year [2], and it is more common in the developed countries compared to the developing countries [3]. In the United States, pancreatic cancer is projected to surpass other leading cancers such as breast and prostate cancers to become the second leading cause of cancer by 2030 [4].

Pancreatic cancer has one of the lowest five-year relative survival rates $(6 \%)$, where the majority of pancreatic cancer patients die within one year from diagnosis $[1,4]$. Some of the reasons for this poor prognosis are (i) inadequate screening procedures [2,5], (ii) ineligibility of cancer patients for surgery [6], (iii) potential risk of other organ damage during surgery [2], (iv) limited treatment options for metastatic pancreatic cancer, and (v) the inability of prompt detection of cancer among earlystage patients $[4,7]$.

The few well-known risk factors of pancreatic cancer are age, smoking, and chronic pancreatitis $[\mathbf{2 , 8}$. Some other factors associated with pancreatic cancers are excess alcohol consumption, coffee drinking, diabetes mellitus, peptic ulcer disease, obesity, H. pylori, gender, race/ethnicity, marital status, insurance status, and aspirin use [2,7,11-14]. 
It is important to look at region-specific estimates for pancreatic cancer as the southern US states have distinct gender, racial/ ethnic, social, and environmental factors influencing disease outcomes compared to other regions in the US. For instance, some of the southern states (e.g., Louisiana, Mississippi) have the highest prevalence of obesity in the US, which could be the consequence of low socioeconomic status and unhealthy dietary patterns in these states [15-18], and black men living in the southern states are more likely to be obese compared to the other states [13]. Additionally, with the exception of Texas, numerous states in the south have some of the lowest median household incomes per year [19], a finding corroborated with12 southern states (e.g., Louisiana, Georgia) having the highest rates of low income students in public school attendance [20].

Pancreatic cancer estimates on incidence, mortality, and relative survival in the general US population have been reported previously $[15,21]$. To our knowledge, no studies have been conducted to shed light on these risk estimates in the southern region of the US, and hence, comparisons could not be made using incidence and mortality to identify the high-risk population in the southern region. For both the regions, the aims of this study were to: (i) calculate the overall, gender, age, and race-specific incidence and mortality rates for 2000 to 2008; (ii) estimate race and gender-specific relative, cause-specific, and conditional survivals for the patients diagnosed with pancreatic cancer between 2000 and 2007; and (iii) explore the trends in the age-adjusted incidence and mortality rates for 2000 to 2008 usingthe population-based Surveillance, Epidemiology, and End Results (SEER) program registries.

\section{Methods}

\section{Description of SEER Data/Study Population}

This study utilized publicly available data from the Surveillance, Epidemiology, and End Results (SEER) program. The program is a population-based cancer registry that aims to cover approximately one quarter of the US population. The cancer cases are reported to the registry from different US regions, and is a source of the most comprehensive incidence and mortality data available to date for various types of cancers prevalent in the United States [22]. The analysis was restricted to the SEER 17 [23] cancer registry to restrict the analysis to the southern United States (Atlanta, Rural Georgia, Louisiana, and Kentucky) and the total US for patients that were diagnosed with pancreatic cancer between 2000 and 2008 that were $\geq 40$ years.

\section{Statistical Analysis}

Race, age, and gender-specific age-adjusted incidence and mortality rates for patients diagnosed with pancreatic cancer between 2000 and 2008 were calculated using the SEER program [22]. Trend analyses were performed to calculate the Annual Percent Change (APC) in the incidence and mortality rates. The APC is a way to understand cancer rates over time, where the rates are assumed to increase at a constant rate from the past year. It is also a measure that is comparable across many scales to compare rare and common types of cancers [24]. The incidence and mortality rates were age-standardized using the 2000 standard US population. Linear regression models were fit to test for linear relationships between time (in years) and pancreatic cancer estimates (incidence and mortality). Joinpoint regression model was utilized to test for non- linear relationship using the Joinpoint Regression Program [25].

For cases diagnosed between 2000 and 2007, the relative, cause-specific, and conditional survivals were calculated. These estimates were calculated for whites and blacks only as the life tables used to calculate the expected survival for other races such as Asians, Pacific Islanders, and Native Americans are not accurate [26]. The relative survival of pancreatic cancer was calculated as a ratio of the proportion of the observed survivors to the proportion of expected survivors. It estimates the effect of a health outcome (e.g., pancreatic cancer) in the absence of competing risks or other causes of death [26]. Conditional survival is a measure of probability of a cohort surviving further than the year of interest, given that the person has survived up to the year of interest after the diagnosis of a disease. It provides valuable information regardinga patient's prognosis for long-term survival [27]. Cancer-specific or cause-specific survival is a net survival from a specific cause or disease (e.g., pancreatic cancer) in the absence of competing causes of death [26].

\section{Results}

Tables 1 and 2 demonstrate the age-adjusted incidence and mortality rates of pancreatic cancer in the SEER 17 southern states and total US, respectively. From 2000 to 2008, there were a total of 11, 273 incident cases and 10,727 deaths reported in the southern states, as compared to the 75, 685 incident cases and 285,696 deaths reported in the total US states. The incidence rates between these two regions did not differ, but the mortality rate in the southern states was slightly higher $(25.5$ per 100,000$)$ than the total US $(24.7$ per 100,000$)$. The incidence and mortality rates were higher among males, older age groups ( $\geq 60$ years) and blacks compared to their counterparts in both of the regions.

The overall three-year survival rates between the two regions did not vary significantly from 2000 to 2007; however, the overall five-year survival rate for the southern states was slightly higher compared to the total US states. Similar patterns in three- and five-year survivals were observed for both the genders and all races between the regions (Table 3). Even though the overall three-year cause-specific survival was higher for the US total states, a reversal in pattern was observed in the five-year causespecific survival (Table 4). Total US black females had a notable increase in three-year cause-specific survival compared to the southern black females. On the contrary, southern white females had a higher five-year cause-specific survival compared to the total US white females (Table 4).

Temporal trends in age-standardized pancreatic cancer incidence and mortality rates for the SEER 17 southern states and total US are depicted by Figures 1 and 4. A significant increase in pancreatic incident rate was observed among all races and all females 
Subi Gandhi, Journal of Cancer Therapeutics \& Research 2018, http://www.hoajonline.com/journals/pdf/2049-7962-6-3.pdf

Table 1. Age-adjusted incidence rates of malignant pancreatic cancer inthe SEER 17 southern and total states (2000-2008).

\begin{tabular}{|c|c|c|c|c|c|c|c|c|}
\hline \multirow[b]{2}{*}{ Variable of Interest } & \multicolumn{4}{|c|}{ Southern United States } & \multicolumn{4}{|c|}{ Total United States } \\
\hline & $\begin{array}{l}\text { Incident } \\
\text { Cases }\end{array}$ & $\begin{array}{l}\text { Incidence } \\
\text { Rate }^{\star}\end{array}$ & 95\% CI & Total & $\begin{array}{l}\text { Incident } \\
\text { Cases }\end{array}$ & $\begin{array}{l}\text { Incidence } \\
\text { Rate }^{\star}\end{array}$ & $95 \% \mathrm{CI}$ & Total \\
\hline Overall & 11,273 & 27.1 & $(26.6,27.6)$ & $44,709,963$ & 75,685 & 27.1 & $26.8,27.2$ & $291,552,608$ \\
\hline \multicolumn{9}{|l|}{ Age at Diagnosis } \\
\hline $40-49$ & 695 & 4.3 & $(4.0,4.6)$ & $16,019,258$ & 3,965 & 3.8 & $(3.6,3.9)$ & $103,900,678$ \\
\hline $50-59$ & 1,881 & 14.6 & $(13.9,15.3)$ & $12,811,739$ & 11,302 & 13.7 & $(13.5,14.0)$ & $81,684,618$ \\
\hline $60-69$ & 2,788 & 36.3 & $(35.0,37.7)$ & $7,775,485$ & 17,234 & 35.5 & $(35.0,36.1)$ & $49,302,933$ \\
\hline $70-79$ & 3,311 & 65.0 & $(62.7,67.2)$ & $5,105,235$ & 22,691 & 65.7 & $(64.8,66.5)$ & $34,514,796$ \\
\hline $80+$ & 2,598 & 86.7 & $(83.4,90.1)$ & $2,998,246$ & 20,403 & 92.3 & $(91.0,93.5)$ & $22,119,583$ \\
\hline \multicolumn{9}{|l|}{ Gender } \\
\hline Male & 5,544 & 30.9 & $(30.1,31.8)$ & $20,807,228$ & 37,180 & 30.7 & $(30.4,31.0)$ & $137,555,475$ \\
\hline Female & 5,729 & 23.9 & $(23.3,24.5)$ & $23,902,735$ & 38,505 & 24.1 & $(23.8,24.3)$ & $153,967,133$ \\
\hline \multicolumn{9}{|l|}{ Race $\dagger$} \\
\hline White & 8,654 & 25.6 & $(25.1,26.2)$ & $34,550,626$ & 62,149 & 26.7 & $(26.5,26.9)$ & $234,835,438$ \\
\hline Black & 2,513 & 34.8 & $(33.4,36.2)$ & $9,177,685$ & 8,106 & 35.8 & $(35.0,36.6)$ & $27,639,558$ \\
\hline $\begin{array}{l}\text { American Indians/ } \\
\text { Alaskan Natives }\end{array}$ & 11 & 8.9 & $(4.3,16.4)$ & 166,443 & 406 & 17.6 & $(15.9,19.5)$ & $3,088,119$ \\
\hline $\begin{array}{l}\text { Asian Americans/ } \\
\text { Pacific Islanders }\end{array}$ & 90 & 18.7 & $(14.5,23.5)$ & 815,210 & 4,803 & 21.5 & $(20.9,22.1)$ & $25,959,494$ \\
\hline
\end{tabular}

Table 2. Age-adjusted mortality rates of pancreatic cancer in the SEER 17 southern and total states (2000-2008).

\begin{tabular}{|c|c|c|c|c|c|c|c|c|}
\hline \multirow[b]{2}{*}{ Variable of Interest } & \multicolumn{4}{|c|}{ Southern United States } & \multicolumn{4}{|c|}{ Total United States } \\
\hline & $\begin{array}{l}\text { Number } \\
\text { of Deaths }\end{array}$ & $\begin{array}{l}\text { Mortality } \\
\text { Rate }^{\star}\end{array}$ & $\begin{array}{l}95 \% \mathrm{CI} \\
\text { (Upper CI, } \\
\text { Lower CI) }\end{array}$ & Total & $\begin{array}{l}\text { Number } \\
\text { of Deaths }\end{array}$ & $\begin{array}{l}\text { Mortality } \\
\text { Rate }^{*}\end{array}$ & $\begin{array}{l}\text { 95\%CI } \\
\text { (Upper CI, } \\
\text { Lower CI) }\end{array}$ & Total \\
\hline Overall & 10,727 & 25.5 & $25.0,25.9$ & $45,635,577$ & 285,696 & 24.7 & $24.6,24.8$ & $1,164,952,027$ \\
\hline \multicolumn{9}{|l|}{ Age at death } \\
\hline $40-49$ & 552 & 3.3 & $(3.1,3.6)$ & $16,331,784$ & 11,930 & 2.9 & $(2.9,3.0)$ & $398,991,966$ \\
\hline $50-59$ & 1,554 & 11.8 & $(11.2,12.4)$ & $13,080,181$ & 37,812 & 11.6 & $(11.5,11.7)$ & $323,246,269$ \\
\hline $60-69$ & 2,514 & 32.2 & $(30.9,33.5)$ & $7,941,016$ & 62,739 & 30.9 & $(30.7,31.2)$ & $204,842,095$ \\
\hline $70-79$ & 3,259 & 62.6 & $(60.5,64.8)$ & $5,217,377$ & 87,502 & 60.1 & $(59.7,60.5)$ & $145,397,271$ \\
\hline $80+$ & 2,848 & 93.0 & $(89.6,96.5)$ & $3,065,219$ & 85,713 & 92.7 & $(92.1,93.3)$ & $92,474,426$ \\
\hline \multicolumn{9}{|l|}{ Gender } \\
\hline Male & 5,273 & 29.5 & $(28.7,30.4)$ & $21,236,132$ & 140,680 & 28.5 & $(28.3,28.7)$ & $46,801,936$ \\
\hline Female & 5,454 & 22.2 & $(21.6,22.8)$ & $24,399,445$ & 145,016 & 21.6 & $(21.5,21.7)$ & $618,150,091$ \\
\hline \multicolumn{9}{|l|}{ Race } \\
\hline White & 8,246 & 24.1 & $(23.6,24.6)$ & $35,214,875$ & 245,327 & 24.3 & $(24.2,24.4)$ & $984,932,912$ \\
\hline Black & 2,394 & 32.9 & $(31.6,34.3)$ & $9,422,465$ & 33,109 & 32.0 & $(31.6,32.3)$ & $124,308,537$ \\
\hline $\begin{array}{l}\text { American Indians/ } \\
\text { Alaskan Natives }\end{array}$ & 17 & 14.3 & $(8.0,23.4)$ & 171,821 & 1,064 & 15.2 & $(14.2,16.2)$ & $9,509,224$ \\
\hline $\begin{array}{l}\text { Asian Americans/ } \\
\text { Pacific Islanders }\end{array}$ & 70 & 15.6 & $(11.7,20.2)$ & 826,416 & 6,196 & 17.3 & $(16.8,17.7)$ & $46,201,354$ \\
\hline
\end{tabular}

${ }^{\star}$ Mortality rates are per 100,000 and age-adjusted to 2000 US standard population; rates calculated for persons 40 years and older.

in the southern states, but an increase in incidence rate was seen for all races, both genders in the total US (Figures 1 and 4). Also, a noteworthy increase in mortality rate was observed in the total US for all races and both the genders, but not in the southern states (Figures 1 and 4).
When the incident rates were compared among the different racial/ethnic groups between the two regions, white females had a significant increase in the incidence rate in the southern states (Figure 2), and such increase was noted for both white males and females in the total US (Figure 5). There was a dramatic 
Table 3. Three and five-year relative survival rates (\%) and confidence intervals for cases $\geq 40$ years that were diagnosed between 2000 and 2007 (SEER 17 southern and total states).

\begin{tabular}{|c|c|c|c|c|c|c|}
\hline & \multicolumn{3}{|c|}{ SEER 17 Southern States } & \multicolumn{3}{|c|}{ SEER 17 Total States } \\
\hline & $\mathbf{N}$ & $\begin{array}{l}\text { 3-year survival } \\
\text { (CI) }\end{array}$ & $\begin{array}{l}\text { 5-year survival } \\
\text { (CI) }\end{array}$ & $\mathbf{N}$ & $\begin{array}{l}\text { 3-year survival } \\
\text { (CI) }\end{array}$ & 5-year survival (CI) \\
\hline Overall & 8,021 & $7.1(6.5,7.7)$ & $5.3(4.8,6.0)$ & 51,774 & $7.2(6.9,7.4)$ & $4.8(4.5,5.0)$ \\
\hline Total Males & 3,882 & $7.0(6.1,7.9))$ & $5.2(4.4,6.1)$ & 25,185 & $7.2(6.8,7.6)$ & $4.7(4.3,5.0)$ \\
\hline Total Females & 4,139 & $7.2(6.4,8.1)$ & $5.4(4.6,6.3)$ & 26,589 & $7.1(6.8,7.5)$ & $4.9(4.5,5.2)$ \\
\hline Whites & 6,098 & $7.4(6.7,8.1)$ & $5.4(4.8,6.2)$ & 42,367 & $7.2(7.0,7.5)$ & $4.9(4.6,5.1)$ \\
\hline Male & 3,011 & $7.2(6.2,8.2)$ & $5.2(4.3,6.2)$ & 20,836 & $7.3(6.9,7.7)$ & $4.8(4.4,5.2)$ \\
\hline Female & 3,087 & $7.6(6.6,8.7)$ & $5.7(4.7,6.7)$ & 21,531 & $7.2(6.8,7.6)$ & $4.9(4.5,5.3)$ \\
\hline Black & 1,845 & $6.1(5.0,7.4)$ & $5.0(3.9,6.3)$ & 5,670 & $6.2(5.5,6.9)$ & $4.0(3.4,4.7)$ \\
\hline Male & 829 & $6.1(4.5,8.0)$ & $5.5(3.9,7.4)$ & 2,521 & $5.6(4.7,6.7)$ & $3.4(2.6,4.5)$ \\
\hline Female & 1,016 & $6.2(4.7,8.0)$ & $4.7(3.3,6.4)$ & 3,149 & $6.7(5.7,7.7)$ & $4.5(3.6,5.4)$ \\
\hline
\end{tabular}

Table 4. Three and five-year cause-specific survival rates (\%) and confidence intervals for cases $\geq 40$ years that were diagnosed between 2000 and 2007 (SEER 17 southern and total states).

\begin{tabular}{|c|c|c|c|c|c|c|}
\hline & \multicolumn{3}{|c|}{ SEER 17 Southern States } & \multicolumn{3}{|c|}{ SEER 17 Total States } \\
\hline & $\mathbf{N}$ & $\begin{array}{l}\text { 3-year survival } \\
\text { (CI) }\end{array}$ & $\begin{array}{l}\text { 5-year survival } \\
\text { (CI) }\end{array}$ & $\mathbf{N}$ & $\begin{array}{l}\text { 3-year survival } \\
\text { (CI) }\end{array}$ & 5-year survival (CI) \\
\hline Overall & 7,965 & $7.3(6.7,8.0)$ & $5.7(5.2,6.4)$ & 52,312 & $7.7(7.5,8.0)$ & $5.3(5.1,5.5)$ \\
\hline Total Males & 3,855 & $7.3(6.4,8.2)$ & $5.6(4.8,6.5)$ & 25,540 & $7.8(7.4,8.1)$ & $5.1(4.8,5.5)$ \\
\hline Total Females & 4,110 & $7.4(6.5,8.3)$ & $5.9(5.1,6.7)$ & 26,772 & $7.7(7.3,8.0)$ & $5.5(5.2,5.8)$ \\
\hline Whites & 6,063 & $7.6(6.9,8.3)$ & $5.9(5.2,6.6)$ & 42,815 & $7.7(7.4,8.0)$ & $5.3(5.0,5.5)$ \\
\hline Male & 2,995 & $7.4(6.4,8.5)$ & $5.6(4.7,6.6)$ & 21,138 & $7.8(7.4,8.2)$ & $5.2(4.8,5.5)$ \\
\hline Female & 3,068 & $7.7(6.7,8.8)$ & $6.1(5.2,7.2)$ & 21,677 & $7.6(7.2,8.0)$ & $5.4(5.0,5.7)$ \\
\hline Black & 1,826 & $6.5(5.3,7.8)$ & $5.3(4.2,6.6)$ & 5,755 & $7.1(6.4,7.9)$ & $5.0(4.3,5.8)$ \\
\hline Male & 819 & $6.5(4.9,8.6)$ & $5.5(3.9,7.5)$ & 2,567 & $6.6(5.5,7.7)$ & $4.1(3.2,5.2)$ \\
\hline Female & 1,007 & $6.5(4.9,8.3)$ & $5.2(3.7,6.9)$ & 3,188 & $7.6(6.6,8.6)$ & $5.7(4.8,6.8)$ \\
\hline
\end{tabular}

decline in the incidence rate among Asian/Pacific Islander males in the southern states, but not in the total US (Figures 2 and 5). Regarding the mortality trends, no significant changes were observed in the rates for different racial/ethnic groups in the southern states (Figure 3); however, significant changes in mortality rates were observed for the whites (overall), and white males and females in the total US (Figure 6).

\section{Discussion}

This study documents the incidence and mortality rates of pancreatic cancer for the southern and the total US among adults 40 years and older. For the same population, temporal trends, and relative, conditional, cause-specific survivals were calculated to explore the underlying factors influencing morbidity and mortality outcomes in various subgroups.

The significant APC change in incidence in the southern states, particularly among whites, could be explained by two major factors. A large health disparity exists in the south; nearly one in five non-elderly southerners do not have health insurance where the largest uninsured group are whites (42\%) compared to the other racial/ethnic groups [28]. Moreover, some southern states have the highest poverty rates in the nation $[\mathbf{1 9}, \mathbf{2 0}, \mathbf{2 8}]$ contributing to some of the worse health outcomes and chronic illnesses compared to the rest of the nation [29].

Women are more likely to get their insurance as dependents compared to men, and their risk of losing health benefits increases if they become widowed, divorced, or if their spouses lose jobs through which insurance is provided [30]. This could be one of the key factors why women that are under 65 years are less likely to have health insurance coverage as compared to their counterparts [31]. Nonetheless, why the increase in APC is much higher in southern women compared to the overall women in the US, and especially among white women, needs to be further elucidated. Previous studies have informed that women generally survive longer in industrialized countries and utilize more health care services compared to their male counterparts [32-34]. Even though women in the south have one the nation's lowest life-expectancies [35], the aforementioned factors could have impacted the increase in incidence rates of pancreatic cancer among females.

Another notable finding was the significant decrease in APC in incidence among male Asians/Pacific Islanders in the south; 


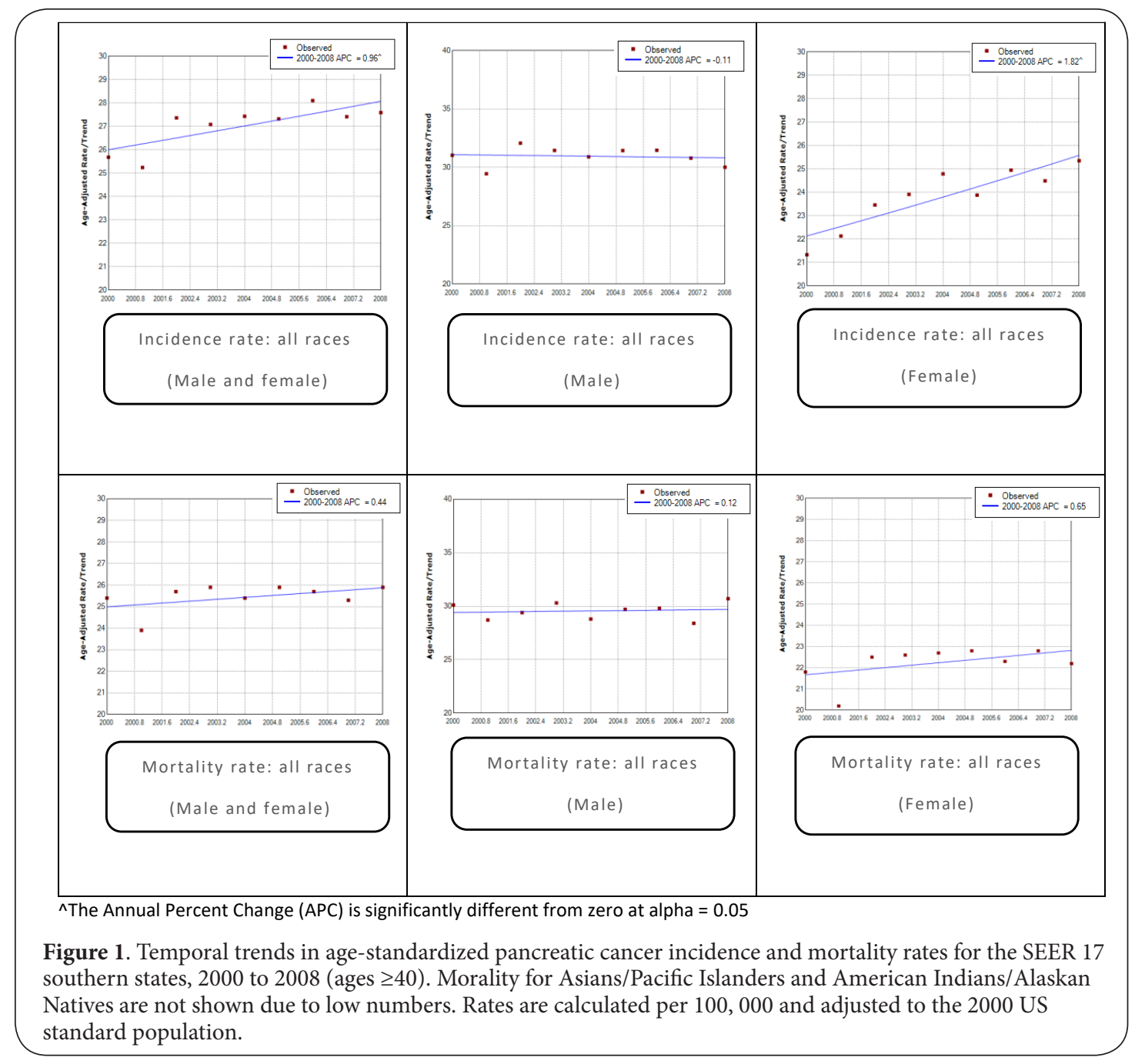

no such pattern was observed for the same ethnic group in the total US. Although the trends in incidence rates for black males in the south and the total US were inconsistent, the incidence rates for black females appeared to be rising (although not significantly) for the two regions, a finding consistent with what was seen for white females. This could indicate that females in the south, more than males as observed nationally, could be at risk for pancreatic cancer.

Consistent with the total US estimates, males and blacks in the southern states had higher incidence and mortality rates from 2000 to 2008 of pancreatic cancer compared to the females and other races respectively. This is also consistent with the presumed risk factors (e.g., pancreatitis, Vitamin D deficiency) that seem to be contributing to the incidence of pancreatic cancer $[36,37]$. The increase in incidence rates of pancreatic cancer observed among whites and blacks could be directly associated with their smoking and drinking behaviors [38]. However, the same association between smoking and pancreatic cancer was not observed among American Indians and Alaskan Natives.
This study should be interpreted in the context of some important limitations. Information on other covariates linked with pancreatic cancer such as smoking and excess alcohol consumption were not considered due to the nature of registry, and only age-adjusted estimates were reported. Additionally, there were a limited number of states that reported to SEER registries for the study period, which could compromise the generalizability of our findings as some of these SEER areas may not be representative of the total US population [39]. However, the SEER database provides an accurate representation of the US cancer population due to its large sample size and long follow-up period. Additionally, for quality control, each SEER registry is routinely audited for data accuracy, and registrars are frequently trained for complete case ascertainment and timely reporting [1]. There is also a possibility of selection bias due to migration and treatment options [40], but due to the high fatality rate of pancreatic cancer and limited treatment options, these biases are less likely to impact the calculated estimates.

This study has two important advantages that make it unique. 
Subi Gandhi, Journal of Cancer Therapeutics \& Research 2018,

http://www.hoajonline.com/journals/pdf/2049-7962-6-3.pdf

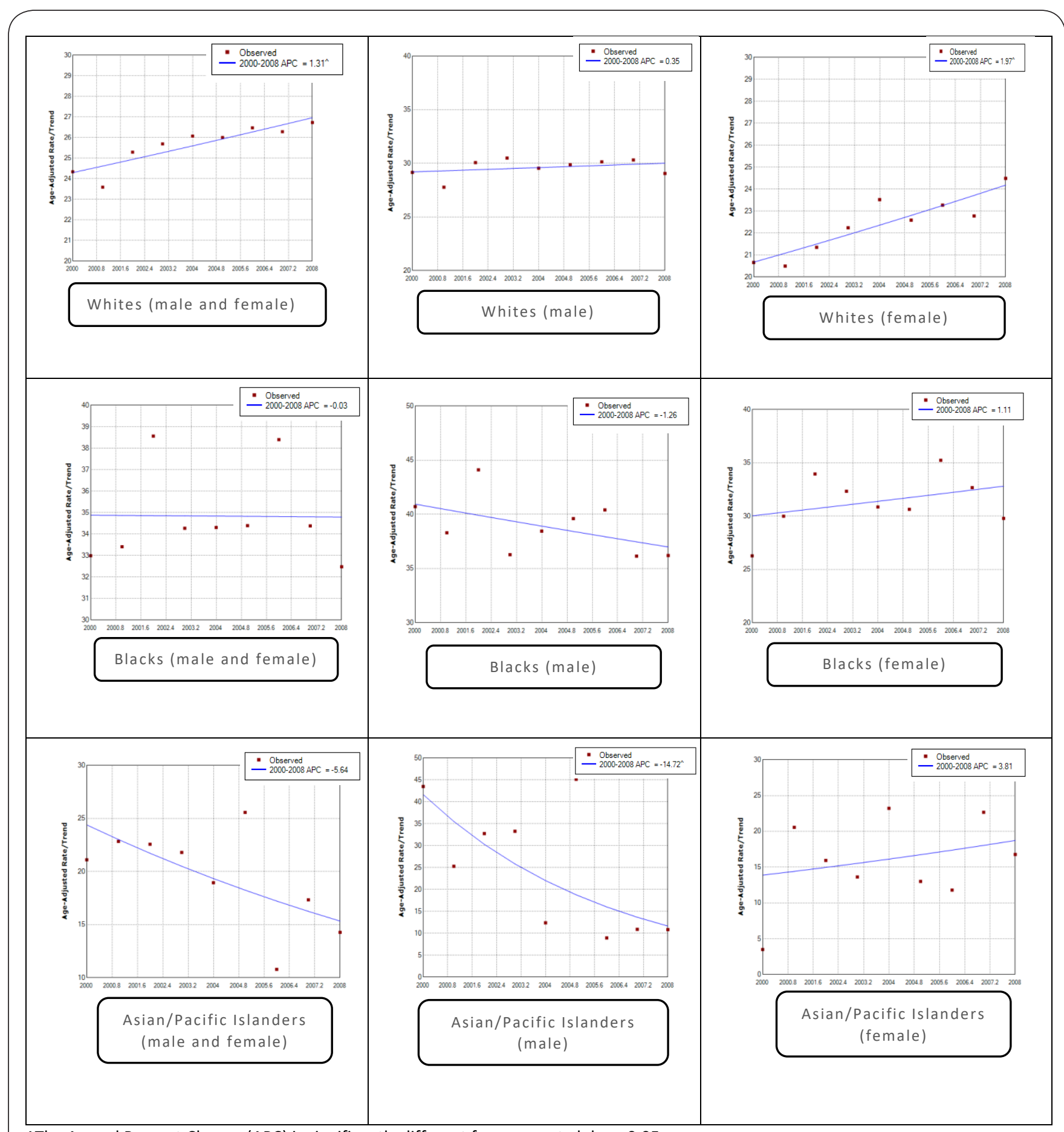

${ }^{\wedge}$ The Annual Percent Change (APC) is significantly different from zero at alpha $=0.05$

Figure 2. Temporal trends in age-standardized pancreatic cancer incidence among White, Black, and Asian/Pacific Islander in SEER 17 southern states, 2000 to 2008 (ages $\geq 40$ ). Rates are calculated per 100, 000 and adjusted to the 2000 US standard population. Incidence for American Indian/Alaskan Native is not shown due to low numbers. 
Subi Gandhi, Journal of Cancer Therapeutics \& Research 2018,

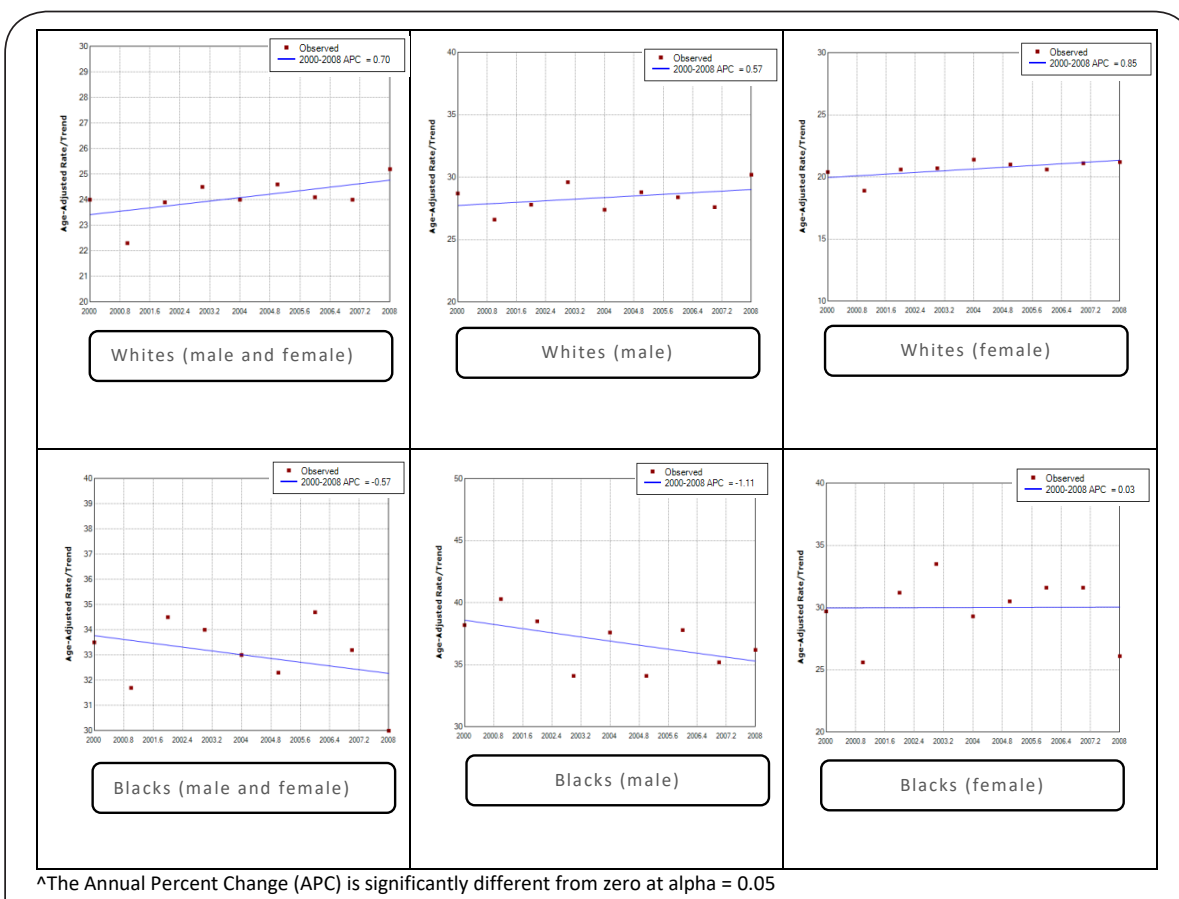

Figure 3. Temporal trends in age-standardized pancreatic cancer mortality among whites and blacks in the SEER 17 southern states, 2000 to 2008 (ages $\geq 40$ ). Morality for Asian/ Pacific Islander and American Indian/Alaskan Native are not shown due to low numbers. Rates are calculated per 100, 000 and adjusted to the 2000 US standard population.

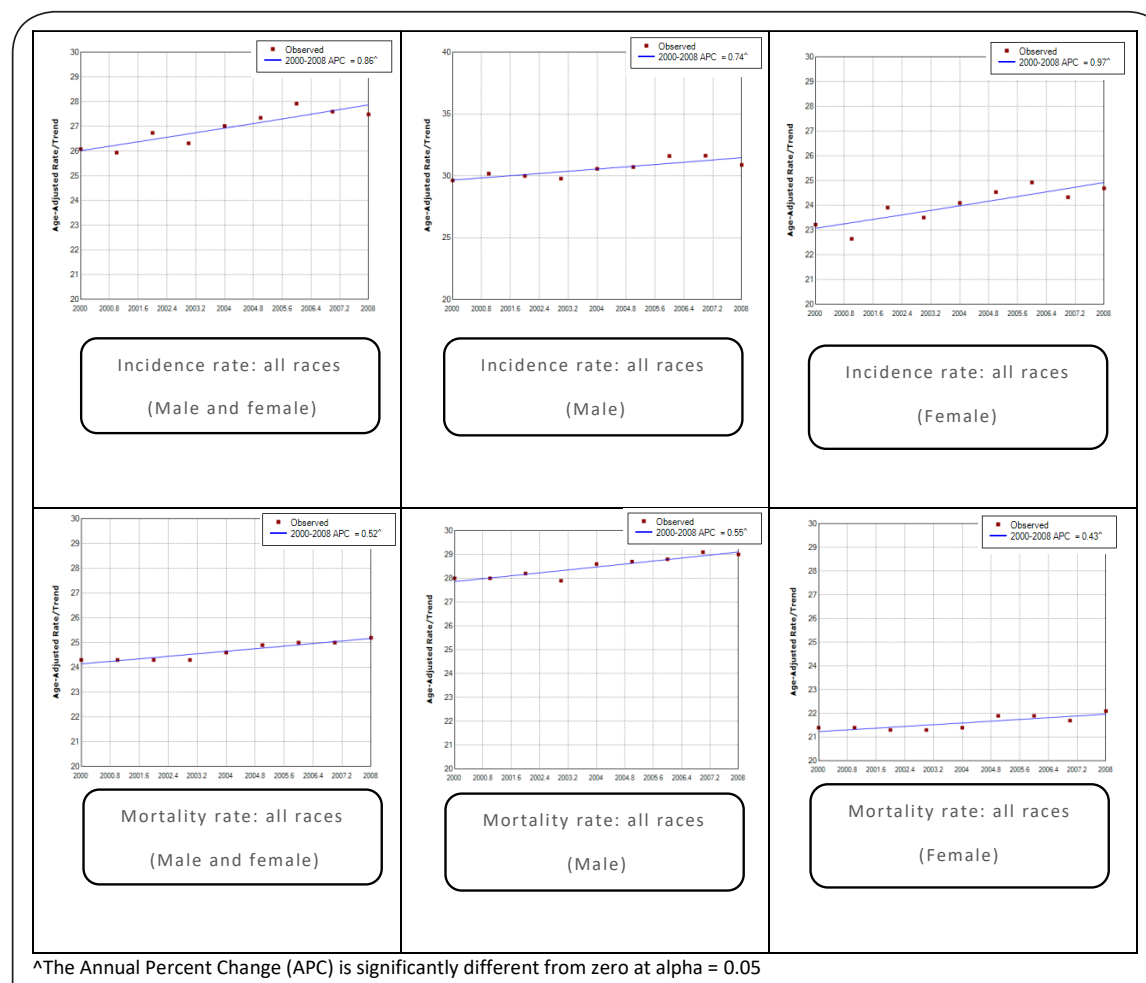

Figure 4. Temporal trends in age-standardized pancreatic cancer incidence and mortality rates for the SEER 17 total states, 2000 to 2008 (ages $\geq 40$ ). Rates are calculated per 100, 000 and adjusted to the 2000 US standard population. 


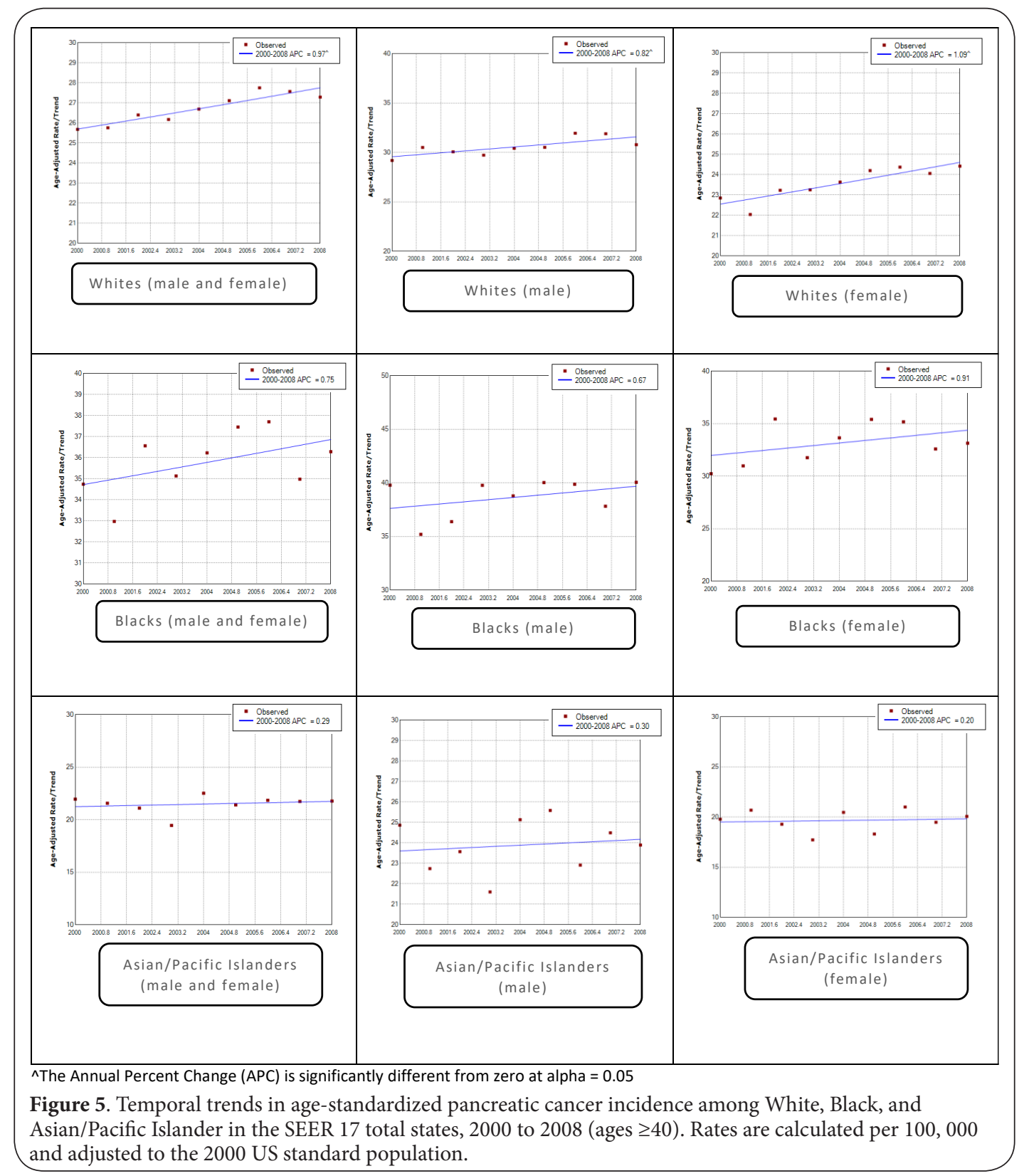

To our knowledge, there is scarce data on gender and racespecific pancreatic cancer incidence, mortality, and survival estimates in the US southern region. The present study is the first to calculate race and gender specific estimates of pancreatic cancer in the southern US, which could not be teased out by looking at the overall US estimates. Second, a standardized protocol was utilized to collect data from the participants [40]. Therefore, the reported estimates are likely valid and reliable.

In essence, this study demonstrated that the pancreatic cancer burden is increasing in the southern US for persons $\geq 40$ years. Females and whites in the south seem to have higher risks of developing this aggressive cancer annually compared to males and other racial groups nationally. These findings could have implications regarding preventive care services and treatment options for particular subgroups in the south. Therefore, clinicians and public health workers should combine their efforts to increase awareness about this cancer, especially among high risk individuals.

\section{Competing interests}

The author declares that she has no competing interests.

\section{Authors' contributions}

The listed author was solely responsible for the research 
Subi Gandhi, Journal of Cancer Therapeutics \& Research 2018, http://www.hoajonline.com/journals/pdf/2049-7962-6-3.pdf

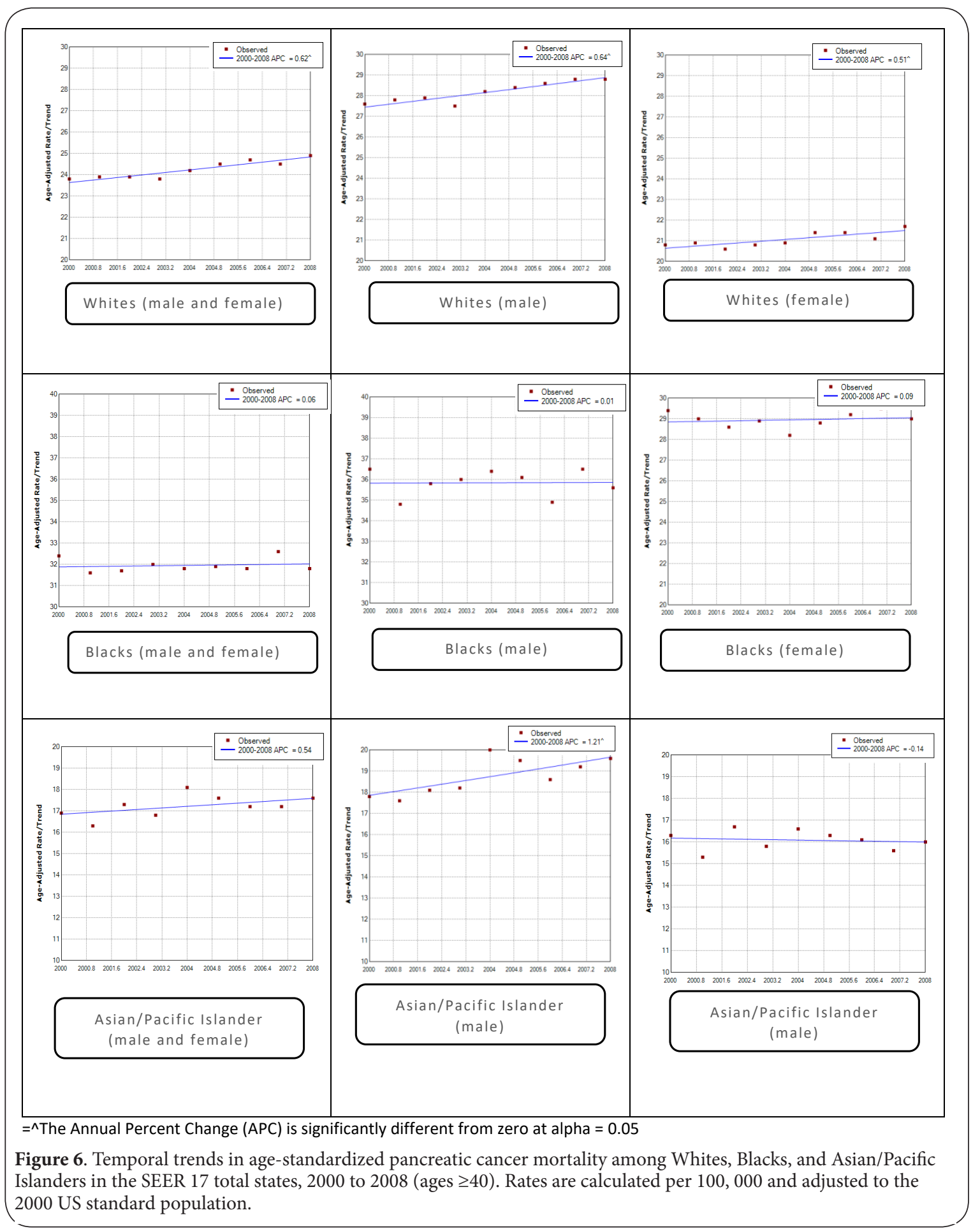

design, analysis, and development of paper, and hence responsible for the final content of the manuscript.

\section{Acknowledgements}

The author thanks the SEER ${ }^{\star}$ Stat Technical Support team at the Surveillance Research Program at the National Cancer Institute. The author also thanks all the colleagues and mentors who have provided guidance during the course of the study but are not included in the list of authors.

\section{Publication history}

Editor: Jianxun Song, Pennsylvania State University College of Medicine, USA.

Received: 30 January 2017 Revised: 01 March 2017

Accepted: 20 June 2017 Published: 01 July 2017 


\section{References}

1. Hariharan D, Saied A and Kocher HM. Analysis of mortality rates for pancreatic cancer across the world. HPB (Oxford). 2008; 10:58-62. Article | PubMed Abstract | PubMed FullText

2. Lowenfels $A B$ and Maisonneuve P. Risk factors for pancreatic cancer. $J$ Cell Biochem. 2005; 95:649-56. | Article | PubMed

3. Siegel R, Ma J, Zou Z and Jemal A. Cancer statistics, 2014. CA Cancer J Clin. 2014; 64:9-29. | Article | PubMed

4. Bosetti C, Bertuccio P, Negri E, La Vecchia C, Zeegers MP and Boffetta P. Pancreatic cancer: overview of descriptive epidemiology. Mol Carcinog. 2012; 51:3-13. | Article | PubMed

5. Raimondi $S$, Maisonneuve $P$ and Lowenfels $A B$. Epidemiology of pancreatic cancer: an overview. Nat Rev Gastroenterol Hepatol. 2009; 6:699-708. | Article | PubMed

6. Akil $L$ and Ahmad HA. Effects of socioeconomic factors on obesity rates in four southern states and Colorado. Ethn Dis. 2011; 21:58-62. | PubMed Abstract | PubMed FullText

7. Centers for Disease Control and Prevention: Adult Obesity Prevalence Maps. 2016.

8. Lowenfels $A B$ and Maisonneuve P. Epidemiology and risk factors for pancreatic cancer. Best Pract Res Clin Gastroenterol. 2006; 20:197-209. | Article | PubMed

9. Ghadirian P, Lynch HT and Krewski D. Epidemiology of pancreatic cancer: an overview. Cancer Detect Prev. 2003; 27:87-93. | Article | PubMed

10. Gold EB and Goldin SB. Epidemiology of and risk factors for pancreatic cancer. Surg Oncol Clin N Am. 1998; 7:67-91. | PubMed

11. Lynch SM, Vrieling A, Lubin JH, Kraft $P$, Mendelsohn JB, Hartge $P$, Canzian F, Steplowski E, Arslan AA, Gross M, Helzlsouer K, Jacobs EJ, LaCroix A and Petersen $\mathrm{G}$ et al. Cigarette smoking and pancreatic cancer: a pooled analysis from the pancreatic cancer cohort consortium. Am J Epidemiol. 2009; 170:403-13. | Article | PubMed Abstract | PubMed FullText

12. Raimondi S, Lowenfels AB, Morselli-Labate AM, Maisonneuve $P$ and Pezzilli R. Pancreatic cancer in chronic pancreatitis; aetiology, incidence, and early detection. Best Pract Res Clin Gastroenterol. 2010; 24:349-58. | Article | PubMed

13. Kelley EA, Bowie JV, Griffith DM, Bruce M, Hill S and Thorpe RJ, Jr. Geography, Race/Ethnicity, and Obesity Among Men in the United States. Am J Mens Health. 2016; 10:228-36. | Article | PubMed

14. Lochan R, Daly AK, Reeves HL and Charnley RM. Genetic susceptibility in pancreatic ductal adenocarcinoma. Br J Surg. 2008; 95:22-32. | Article | PubMed

15. Zhang J, Dhakal I, Yan H, Phillips M and Kesteloot H. Trends in pancreatic cancer incidence in nine SEER Cancer Registries, 1973-2002. Ann Oncol. 2007; 18:1268-79. | Article | PubMed

16. Shopland DR, Hartman AM, Gibson JT, Mueller MD, Kessler LG and Lynn WR. Cigarette smoking among U.S. adults by state and region: estimates from the current population survey. J Natl Cancer Inst. 1996; 88:174858. | PubMed

17. Akil $L$ and Ahmad HA. Effects of socioeconomic factors on obesity rates in four southern states and Colorado. Ethn Dis. 2011; 21:58-62. | PubMed Abstract | PubMed FullText

18. Centers for Disease Control and Prevention: Adult Obesity Prevalence Maps. 2016.

19. United States Census Bureau. Median Household Income in the Past 12 Months for the United States and Puerto Rico. 2015.

20. Education Foundation: A new majority: Low income students now a majority in the nation's public schools. 2015.

21. Howlader, N., Noone, A. M., Krapcho, M., Neyman, N., Aminou, R., Waldron, W., Altekruse, S. F., Kosary, C. L., Ruhl, J., Tatalovich, Z., Cho, H., Mariotto, A., Eisner, M. P., Lewis, D. R., Chen, H. S., Feuer, E. J., Cronin, K. A., and Edwards, B. K. (eds). SEER Cancer Statistics Review, 1975-2008, National Cancer Institute. Bethesda, MD.

22. Overview of SEER program.

23. National Cancer Institute Surveillance, Epidemiology, and End Results
(SEER) Program: (www.seer.cancer.gov) SEER*Stat Database: Incidence - SEER 17 Regs Public-Use, Nov 2005 Sub (1973-2003 varying), National Cancer Institute, DCCPS, Surveillance Research Program, Cancer Statistics Branch, released April 2006, based on the November 2005 submission. | Website

24. Average Annual Percent Change (AAPC).

25. Joinpoint Regression Program, Version 4.3.1. Statistical Research and Applications Branch, National Cancer Institute. 2016.

26. Ries LAG, Young JL, Keel GE, Eisner MP, Lin YD and Horner M-J. SEER Survival Monograph: Cancer Survival Among Adults: U.S. SEER Program, 1988-2001, Patient and Tumor Characteristics. National Cancer Institute, SEER Program. NIH Pub. No. 076215. 2007.

27. Hieke S, Kleber M, Konig C, Engelhardt $M$ and Schumacher $M$. Conditional Survival: A Useful Concept to Provide Information on How Prognosis Evolves over Time. Clin Cancer Res. 2015; 21:1530-6. | Article I PubMed

28. The Henry J Kaiser Family Foundation. Health Coverage and Care in the South in 2014 and Beyond. 2014.

29. Health and Health Coverage in the South: A Data Update.

30. The Henry J. Kaiser Family Foundation. Women's Health Insurance Coverage.

31. National Health Interview Survey Early Release Program: Early Release of Selected Estimates Based on Data from the $\mathbf{2 0 1 5}$ National Health Interview Survey.

32. Eskes $\mathrm{T}$ andHaanen $\mathrm{C}$. Why do women live longer than men? Eur J ObstetGynecolReprodBiol. 2007; 133:126-33.

33. Micheli A, Mariotto A, Giorgi Rossi A, Gatta G and Muti P. The prognostic role of gender in survival of adult cancer patients. EUROCARE Working Group. Eur J Cancer. 1998; 34:2271-8. | Article | PubMed

34. Bertakis KD, Azari R, Helms LJ, Callahan EJ and Robbins JA. Gender differences in the utilization of health care services. J Fam Pract. 2000; 49:147-52. | PubMed

35. Yadav $D$ and Lowenfels $A B$. The epidemiology of pancreatitis and pancreatic cancer. Gastroenterology. 2013; 144:1252-61. | Article | PubMed Abstract | PubMed FullText

36. Grant WB and Peiris AN. Differences in vitamin D status may account for unexplained disparities in cancer survival rates between African and white Americans. Dermatoendocrinol. 2012; 4:85-94. | Article | PubMed Abstract | PubMed FullText

37. Yadav D, Hawes RH, Brand RE, Anderson MA, Money ME, Banks PA, Bishop MD, Baillie J, Sherman S, DiSario J, Burton FR, Gardner TB, Amann ST, Gelrud A, Lawrence C, Elinoff B, Greer JB, O'Connell M, Barmada MM, Slivka A and Whitcomb DC. Alcohol consumption, cigarette smoking, and the risk of recurrent acute and chronic pancreatitis. Arch Intern Med. 2009; 169:1035-45. | Article | PubMed

38. State Health Facts. Life expectancy at birth (in years). Yadav, D., andLowenfels, A. B. (2013). The epidemiology of pancreatitis and pancreatic cancer. Gastroenterology, 144(6), 1252-1261.

39. Kuo TM and Mobley LR. How generalizable are the SEER registries to the cancer populations of the USA? Cancer Causes Control. 2016; 27:111726. | Article | PubMed Abstract | PubMed FullText

40. NCI SEER Public-Use Data: Applications and Limitations in Oncology Research.

\section{Citation:}

Gandhi S. Pancreatic Cancer Incidence, Mortality, and Survival in the SEER 17 Southern and Total United States (2000-2008). J Cancer Ther Res. 2017; 6:3. http://dx.doi.org/10.7243/2049-7962-6-3 